\title{
A standardized nomenclature for cervical spine soft-tissue release and osteotomy for deformity correction
}

\author{
Clinical article
}

\author{
Christopher P. Ames, M.D., ${ }^{1}$ Justin S. Smith, M.D., Ph.D., ${ }^{2}$ Justin K. Scheer, B.S., ${ }^{3}$ \\ Christopher I. Shaffrey, M.D. ${ }^{2}$ Virginie Lafage, Ph.D.,${ }^{4}$ Vedat Deviren, M.D.,${ }^{5}$ \\ Bertrand Moal, M.S. ${ }^{4}$ Themistocles Protopsaltis, M.D., ${ }^{4}$ Praveen V. Mummaneni, M.D., ${ }^{1}$ \\ Gregory M. Mundis Jr., M.D. ${ }^{6}$ Richard Hostin, M.D. ${ }^{7}$ Eric Klineberg, M.D. ${ }^{8}$ \\ Douglas C. Burton, M.D. ${ }^{9}$ Robert Hart, M.D. ${ }^{10}$ Shay Bess, M.D. ${ }^{11}$ Frank J. Schwab, M.D. ${ }^{4}$ \\ and the InTERnational SPINe STUdy Group
}

${ }^{I}$ Department of Neurological Surgery, University of California, San Francisco, California; ${ }^{2}$ Department of Neurosurgery, University of Virginia Health System, Charlottesville, Virginia; ${ }^{3}$ University of California, San Diego, School of Medicine, San Diego, California; ${ }^{4}$ Department of Orthopaedic Surgery, NYU Hospital for Joint Diseases, New York, New York; ${ }^{5}$ Department of Orthopedic Surgery, University of California, San Francisco, California; ${ }^{6}$ San Diego Center for Spinal Disorders, La Jolla, California; ${ }^{7}$ Department of Orthopaedic Surgery, Baylor Scoliosis Center, Plano, Texas; ${ }^{8}$ Department of Orthopaedic Surgery, University of California, Davis, Sacramento, California; ${ }^{9}$ Department of Orthopaedic Surgery, University of Kansas Medical Center, Kansas City, Kansas; ${ }^{10}$ Department of Orthopaedic Surgery, Oregon Health \& Science University, Portland, Oregon; and ${ }^{11}$ Rocky Mountain Hospital for Children, Denver, Colorado

\begin{abstract}
Object. Cervical spine osteotomies are powerful techniques to correct rigid cervical spine deformity. Many variations exist, however, and there is no current standardized system with which to describe and classify cervical osteotomies. This complicates the ability to compare outcomes across procedures and studies. The authors' objective was to establish a universal nomenclature for cervical spine osteotomies to provide a common language among spine surgeons.

Methods. A proposed nomenclature with 7 anatomical grades of increasing extent of bone/soft tissue resection and destabilization was designed. The highest grade of resection is termed the major osteotomy, and an approach modifier is used to denote the surgical approach(es), including anterior (A), posterior (P), anterior-posterior (AP), posterior-anterior (PA), anterior-posterior-anterior (APA), and posterior-anterior-posterior (PAP). For cases in which multiple grades of osteotomies were performed, the highest grade is termed the major osteotomy, and lower-grade osteotomies are termed minor osteotomies. The nomenclature was evaluated by 11 reviewers through 25 different radiographic clinical cases. The review was performed twice, separated by a minimum 1-week interval. Reliability was assessed using Fleiss kappa coefficients.

Results. The average intrarater reliability was classified as "almost perfect agreement" for the major osteotomy $(0.89$ [range 0.60-1.00]) and approach modifier (0.99 [0.95-1.00]); it was classified as "moderate agreement" for the minor osteotomy $(0.73$ [range $0.41-1.00])$. The average interrater reliability for the 2 readings was the following: major osteotomy, 0.87 ("almost perfect agreement"); approach modifier, 0.99 ("almost perfect agreement"); and minor osteotomy, 0.55 ("moderate agreement"). Analysis of only major osteotomy plus approach modifier yielded a classification that was "almost perfect" with an average intrarater reliability of $0.90(0.63-1.00)$ and an interrater reliability of 0.88 and 0.86 for the two reviews.

Conclusions. The proposed cervical spine osteotomy nomenclature provides the surgeon with a simple, standard description of the various cervical osteotomies. The reliability analysis demonstrated that this system is consistent and directly applicable. Future work will evaluate the relationship between this system and health-related quality of life metrics.
\end{abstract} (http://thejns.org/doi/abs/10.3171/2013.5.SPINE121067)

\section{KEY WORdS • cervical • deformity • nomenclature $\bullet \quad$ osteotomy $\bullet \quad$ spine $\bullet$ surgery}

$\mathrm{D}$ ESPITE the complexity of CSD and the substantial impact on patient quality of life, there exists no comprehensive classification system to serve as the basis of communication among physicians and to facilitate effective clinical and radiographic study of patients with these deformities. Without a standardized classification system, studies of CSD may suffer from heterogeneity that compromises the study findings and negatively impacts

Abbreviation used in this paper: $\mathrm{CSD}=$ cervical spine deformity. communication of the results. Other spinal conditions, including adult and pediatric scoliosis, spondylolisthesis, and trauma have benefitted substantially from standardized classification systems (F Schwab, B Blondel, E Chay, et al., unpublished data, 2012). ${ }^{23,28,29,48}$ An established and validated classification system for CSD could prove fundamentally valuable to future study of this condition.

This article contains some figures that are displayed in color online but in black-and-white in the print edition. 
There are several important preliminary steps that should be completed prior to developing a useful deformity classification based upon disability drivers and outcomes. Primary among these is the development of an agreed-upon nomenclature in this process to allow direct outcome comparisons among clearly defined techniques. The primary techniques for correction of rigid CSDs are osteotomies, $1,3,7,9,12,14,20,31,32,34,35,39,40,51,56,59,61,62$ which have many variations and lack a standardized nomenclature. As a first step toward the long-term goal of developing a cervical deformity classification system, our objective in the present study was to establish a standardized nomenclature for cervical spine osteotomies to provide a common language among spine surgeons.

\section{Methods}

Institutional review board approval for the study was obtained through the University of California, San Francisco.

\section{Description of the Nomenclature System}

The proposed cervical osteotomy nomenclature (Table 1, Fig. 1) was developed with the goals of being anatomically based, graduated in degree of resection, and reasonably comprehensive. The system was developed and optimized by group consensus after discussion of case examples. This nomenclature is not intended to describe indications for surgery or to assist in determination of optimal surgical approaches. Instead, it should be viewed as providing a common language to more effectively and objectively communicate anatomical resections. There are 7 proposed anatomical grades of resection (Fig. 1), representing progressive degrees of potential destabilization. Since procedures for a given case may involve combinations of resection types, the highest grade of osteotomy performed is designated as the "major osteotomy," while other lower grades of osteotomies performed are designated as "minor osteotomies." In addi- tion, modifiers are included in the system to designate the surgical approach(es) (anterior [A], posterior [P], anteriorposterior [AP], posterior-anterior [PA], anterior-posterioranterior [APA], and posterior-anterior-posterior [PAP]).

\section{Grade 1: Partial Facet Joint Resection}

A Grade 1 osteotomy (Fig. 2) includes a partial facet joint resection. This may be achieved through an anterior approach that includes a discectomy and partial uncovertebral joint resection, or through a posterior approach that includes facet capsule resection or partial facet resection. Although this procedure has limited capacity for deformity correction, it may be applied over multiple levels to cumulatively assist in correcting alignment, and, when applied posteriorly, it offers the potential to promote fusion through cartilage removal from the facet surface. Whether performed anteriorly or posteriorly, Grade 1 osteotomies require mobility (nonfusion) of the opposite column (posterior or anterior, respectively) to achieve the desired alignment change. Grade 1 osteotomies may be performed through anterior or posterior approaches (Modifiers A or P) or through combinations of both approaches (that is, AP, PA, APA, or PAP).

Since Grade 1 osteotomies are most commonly performed in combination with other osteotomies and release techniques, ${ }^{9,37}$ few reports have detailed their isolated application for cervical deformity correction. Poulter et al. reported the successful treatment of severe cervical hyperextension disorder through release of the posterior cervical musculature, multilevel posterior Grade 1 osteotomies, and fixation in a halo collar after bringing the head into a neutral position. ${ }^{42}$

\section{Grade 2: Complete Facet Joint Resection/Ponte Osteotomy}

A Grade 2 osteotomy involves resection of both superior and inferior facets at a given spinal segment (Fig. 3). Other soft-tissue and bony elements may also be resected, including the ligamentum flavum, lamina, and

\section{TABLE 1: Description of cervical osteotomy nomenclature*}

\begin{tabular}{|c|c|c|c|}
\hline $\begin{array}{l}\text { Osteotomy } \\
\text { Grade }\end{array}$ & Resection & Description & Surgical Approach \\
\hline 1 & partial facet joint resection & $\begin{array}{l}\text { anterior cervical discectomy including partial uncovertebral joint resection, } \\
\text { posterior facet capsule resection, or partial facet resection }\end{array}$ & A, P, AP, PA, APA, PAP \\
\hline 2 & $\begin{array}{l}\text { complete facet joint/Ponte os- } \\
\text { teotomy }\end{array}$ & $\begin{array}{l}\text { both superior \& inferior facets at a given segment are resected; other poste- } \\
\text { rior elements of vertebra including lamina \& spinous processes may also } \\
\text { be resected }\end{array}$ & $P, A P, P A, A P A, P A P$ \\
\hline 3 & partial or complete corpectomy & partial or complete corpectomy, including discs above \& below & A, AP, PA, APA, PAP \\
\hline 4 & $\begin{array}{l}\text { complete uncovertebral joint re- } \\
\text { section to transverse foramen }\end{array}$ & $\begin{array}{l}\text { anterior osteotomy through lat body \& uncovertebral joints \& into transverse } \\
\text { foramen }\end{array}$ & A, PA, AP, APA, PAP \\
\hline 5 & opening wedge osteotomy & $\begin{array}{l}\text { complete posterior element resection w/ osteoclastic fracture \& open wedge } \\
\text { creation }\end{array}$ & P, PA, AP, APA, PAP \\
\hline 6 & closing wedge osteotomy & $\begin{array}{l}\text { complete posterior element resection \& pedicle resection w/ closing wedge } \\
\text { creation }\end{array}$ & $P, P A, A P, A P A, P A P$ \\
\hline 7 & $\begin{array}{l}\text { complete vertebral column re- } \\
\text { section }\end{array}$ & $\begin{array}{l}\text { resection of } 1 \text { or more entire vertebral bodies \& discs including complete } \\
\text { uncovertebral joint \& posterior lamina and facets }\end{array}$ & AP, PA, APA, PAP \\
\hline
\end{tabular}

* $\mathrm{A}=$ anterior; $\mathrm{AP}=$ anterior-posterior; $\mathrm{APA}=$ anterior-posterior-anterior; $\mathrm{P}=$ posterior; $\mathrm{PA}=$ posterior-anterior; $\mathrm{PAP}=$ posterior-anterior-posterior. 

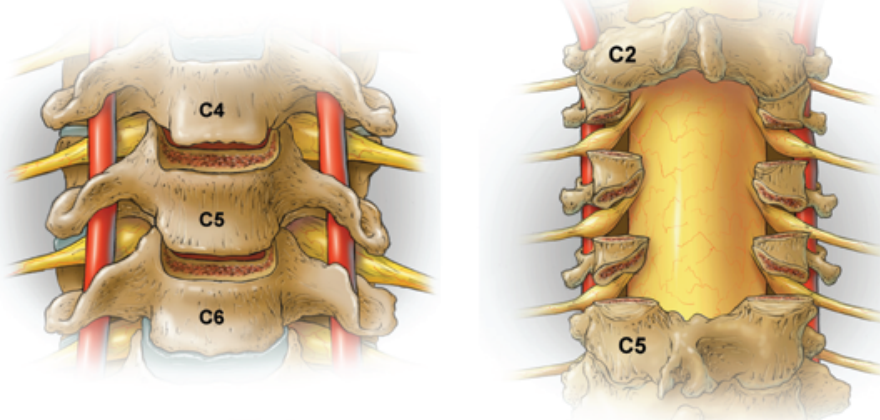

Grade-2

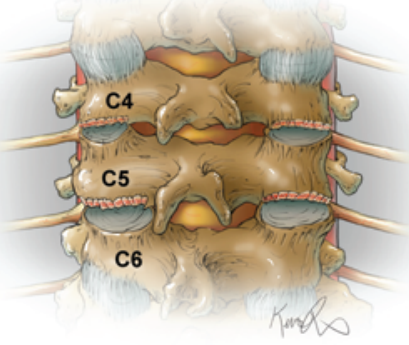

Grade-1

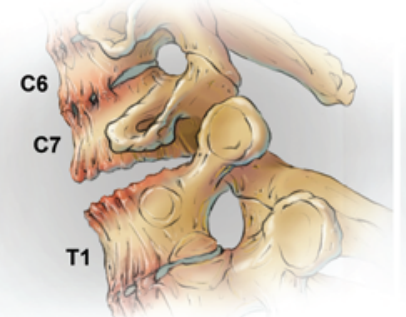

Grade-5
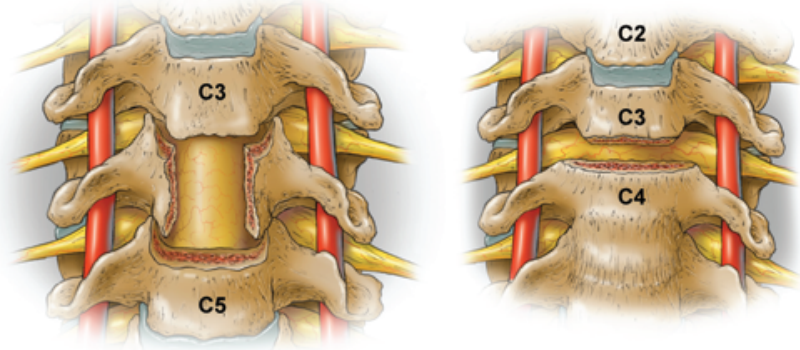

Grade-3

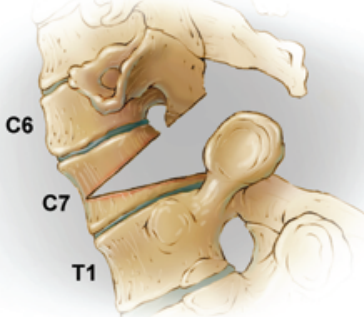

Grade-6
Grade-4

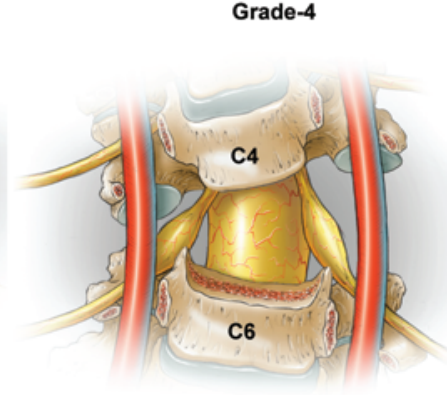

Grade-7

Fig. 1. Illustrations representing the cervical osteotomy nomenclature, which includes 7 grades of resection for progressive degrees of potential destabilization. See text for further description of each grade.

A
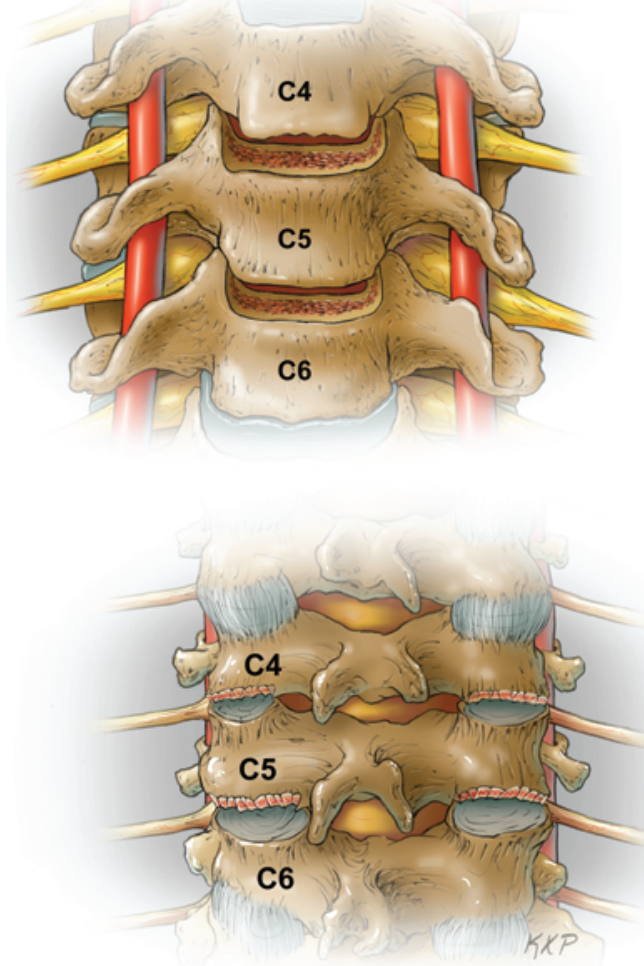

Grade-1

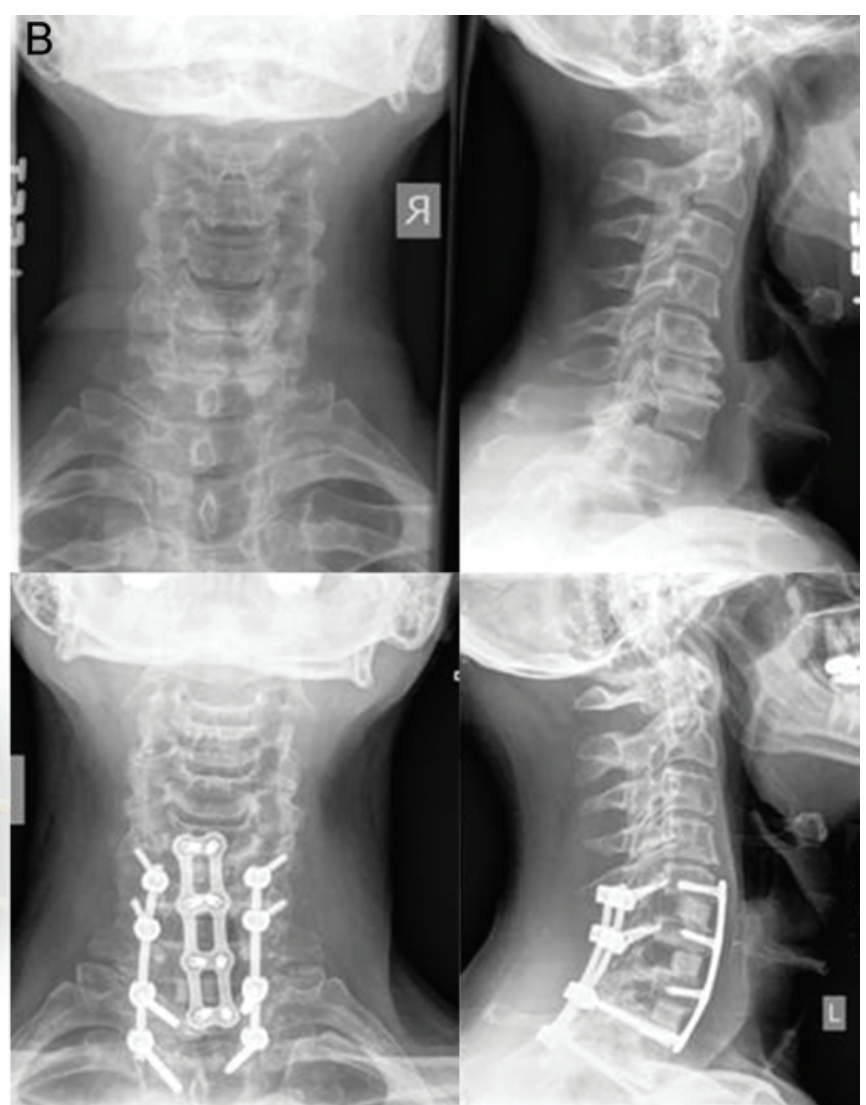
FIG. 2. A: Grade 1 osteotomy, partial facet joint resection. B: Preoperative and postoperative radiographs of a patient
reated with a 3-stage procedure. Stage 1 entailed partial facet resections from C-5 to $T-1, C 6-T 1$ laminectomies, and posterior segmental instrumentation and fusion from C-5 to T-2. Stage 2 involved an anterior cervical discectomy and fusion with plating from C-5 to T-2. Stage 3 necessitated placement of rods, final posterior correction, and posterior spinal fusion from C-5 to T-2. The classification for this case is 1PAP (with no minor osteotomies). 


\section{P. Ames et al.}
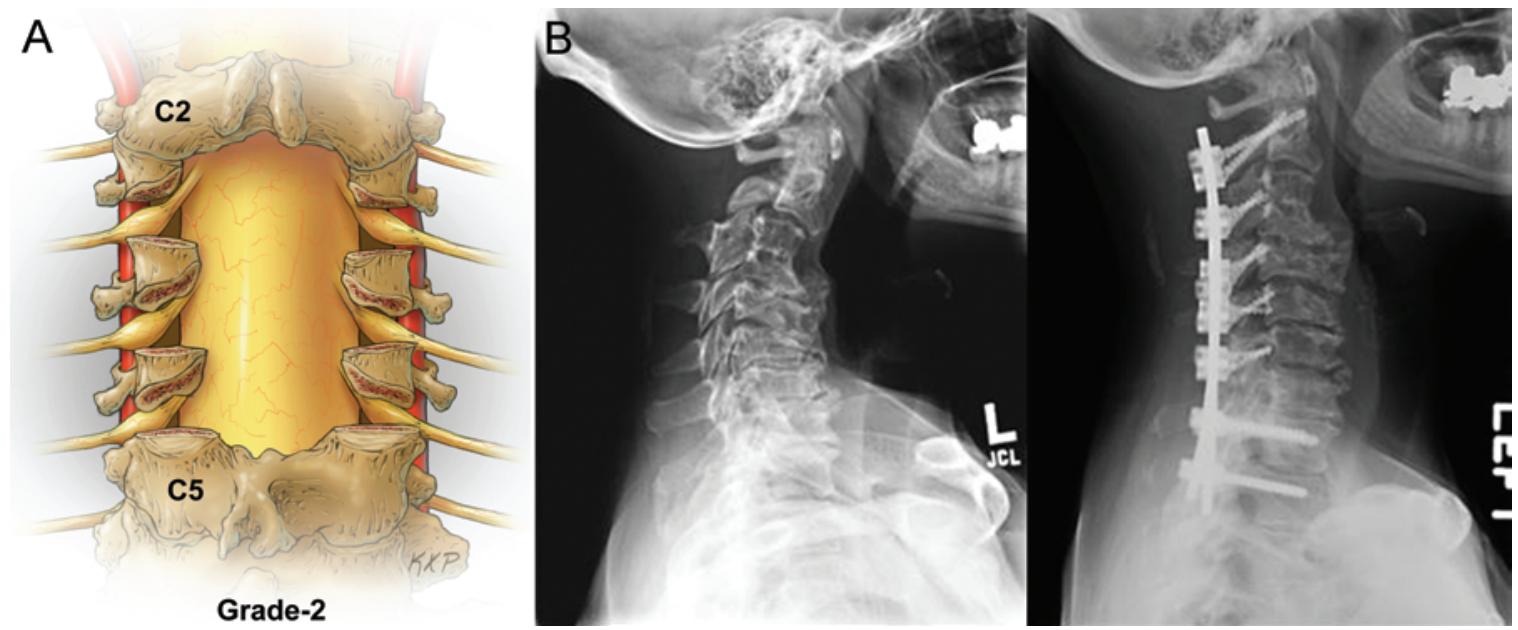

FIG. 3. A: Grade 2 osteotomy, complete facet joint/Ponte osteotomy. B: Preoperative and postoperative radiographs of a patient treated with multilevel complete facet resection and posterior segmental instrumentation and fusion from C2-T2. The classification for this case is $2 \mathrm{P}$ (with no minor osteotomies).

spinous process; however, osteotomies that include any resection of the vertebral body are not included in this grade category. Similar to Grade 1 osteotomies, Grade 2 osteotomies require at least some degree of anterior column mobility. Grade 2 osteotomies are often performed at multiple levels to facilitate a greater magnitude of deformity correction. A posterior approach (Modifier P) is used for Grade 2 osteotomies, but these may be performed in combination with an anterior soft-tissue release (Modifiers AP, PA, APA, or PAP).

Numerous previous reports have described osteotomy techniques for the lumbar spine that are commonly applied in an analogous fashion to the cervical spine, ${ }^{15,17,36,40}$ and several of these would be classified within the Grade 2 osteotomy category. These include the Smith-Petersen osteotomy, ${ }^{54}$ which involves wide resection of the posterior elements, including the lamina and bilateral facets, and, as initially described, was applied to multiple levels through previously fused facets in upper levels of the lumbar spine., ${ }^{7,20}$ Osteotomies similar to the Smith-Petersen osteotomy but through unfused articular processes have been described, including the Chevron osteotomy ${ }^{4}$ and the extension osteotomy. ${ }^{30}$ Similarly, for polysegmen- tal $^{44}$ and Ponte ${ }^{12}$ osteotomies, bone is removed from the articular processes and the interlaminar space to achieve deformity correction. These osteotomies would also be categorized as Grade 2 resections.

\section{Grade 3: Partial or Complete Corpectomy}

A Grade 3 osteotomy includes partial or complete resection of a vertebral body, including the adjacent discs (Fig. 4). Grade 3 osteotomies cannot only enable substantial release and correction of deformity, but may also facilitate decompression of the spinal canal and foramina. Mobility of the posterior elements is necessary to achieve optimal deformity correction with a Grade 3 osteotomy. A custom-cut fibular strut allograft spacer or expandable cage is typically placed in the corpectomy defect to provide structural support and to facilitate arthrodesis. ${ }^{40}$ An anterior approach (Modifier A) is used for Grade 3 osteotomies, but these may be performed in combination with a posterior release (Modifiers AP, PA, APA, or PAP).

Multiple reports have described the use of Grade 3 osteotomies for correction of a cervical deformity. ${ }^{37,39,40,56}$ Among the largest series is that of Nottmeier et al., ${ }^{39}$ in which 41 patients with kyphotic deformity underwent

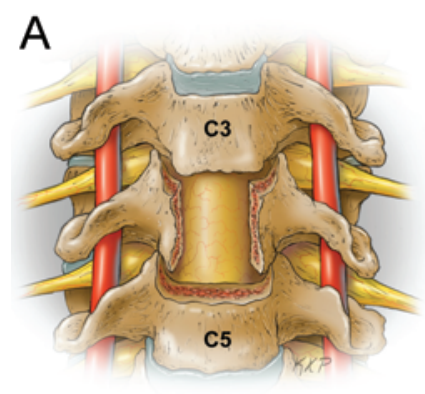

Grade-3

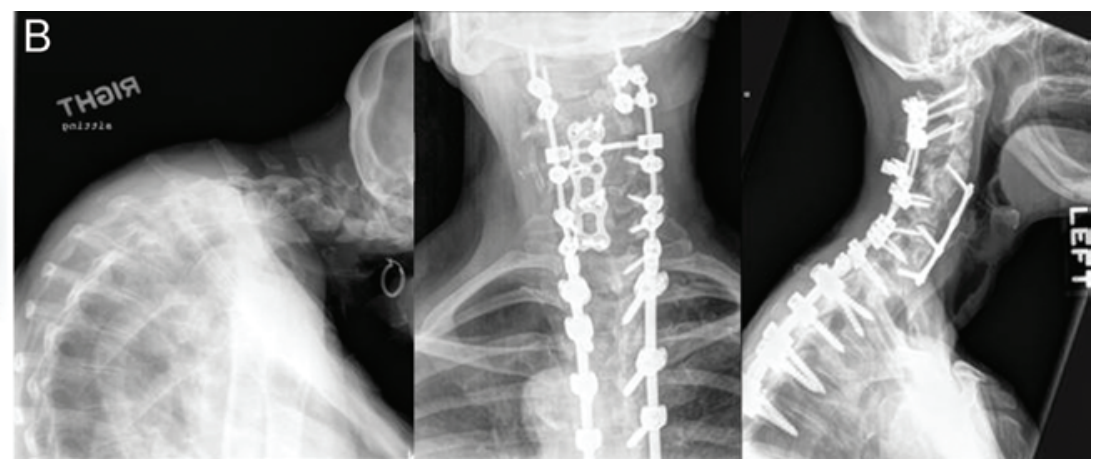
FIG. 4. A: Grade 3 osteotomy, partial or complete corpectomy. B: Preoperative and postoperative radiographs of a patient
reated with a 3-stage procedure. Stage 1 entailed complete facet resection from C-4 to T-4, posterior segmental instrumentation from C- 1 to T-6, and foraminotomies at C-2 to C-3 and C7-T1. Stage 2 involved C-4 corpectomy and anterior cervical discectomy and fusion with plating from C-3 to C-7. Stage 3 necessitated posterior rod placement, final correction, and fusion from C-1 to T-6. The classification for this case is 3PAP (with Grade 2 minor osteotomies). 
combined anterior and posterior reconstruction, including one or more Grade 3 osteotomies in approximately one-half of the cases.

\section{Grade 4: Complete Uncovertebral Joint Resection to the Transverse Foramen}

A Grade 4 osteotomy includes an anterior bony resection through the lateral body and uncovertebral joints and into the transverse foramen (Fig. 5). Grade 4 osteotomies can be particularly helpful for deformity correction in patients with a completely ankylosed anterior column. A Grade 4 osteotomy contrasts with an anterior Grade 1 osteotomy in that Grade 1 osteotomy involves only partial uncovertebral joint resection; a Grade 4 osteotomy includes lateral extension across the uncovertebral joints and into the transverse foramen. This may include skeletonization of the vertebral arteries bilaterally as a means of minimizing the risk of arterial kinking, especially at the apex in cases of severe kyphosis. An anterior approach (Modifier A) is used for Grade 4 osteotomies, but these may be performed in combination with a posterior release (Modifiers AP, PA, APA, or PAP).

O'Shaughnessy et al. reported a series of 16 patients who were surgically treated for fixed cervical kyphosis with myelopathy. ${ }^{40}$ All of the patients underwent both anterior and posterior surgical procedures, and the authors described the frequent application of combinations of anterior Grade 1 and Grade 4 osteotomies to achieve release of the ankylosed anterior column.

\section{Grade 5: Opening Wedge Osteotomy}

A Grade 5 osteotomy includes complete resection of the posterior elements, including lamina, spinous process, and facets, followed by osteoclastic fracture and creation of an anterior wedge in the anterior column as in cases with ankylosing spondylitis (Fig. 6). Typically, the Grade 5 osteotomy includes removal of the inferior lamina of C-6, the entire C-7 lamina, and the superior portion of the T-1 lamina. The $\mathrm{C}-8$ nerve roots are generously decompressed to prevent compression on closure of the osteotomy. This osteotomy type has a fulcrum of rotation in the middle column, with lengthening of the anterior column and shortening of the spinal column. A posterior approach (Modifier P) is used for Grade 5 osteotomies, but these may be performed in combination with an anterior release (Modifiers AP, PA, APA, or PAP).

The Grade 5 osteotomy for correction of cervical deformity was first reported in 1953 by Mason et al., who established the importance of performing this osteotomy at the cervicothoracic junction, below the entrance of the vertebral arteries into the transverse foramen at the C-6 vertebra. ${ }^{31}$ Urist subsequently reported the same surgical technique in 1958, with the use of a local anesthetic in a seated, awake patient. ${ }^{61}$ Multiple modifications to the technique of Urist have been reported subsequently. ${ }^{27,32,35,50,51,61}$ Several series of patients with cervical deformity treated with a Grade 5 osteotomy have been reported. ${ }^{1,11,32,34,35,50,51}$

Grade 6: Closing Wedge Osteotomy

A Grade 6 osteotomy involves complete removal of
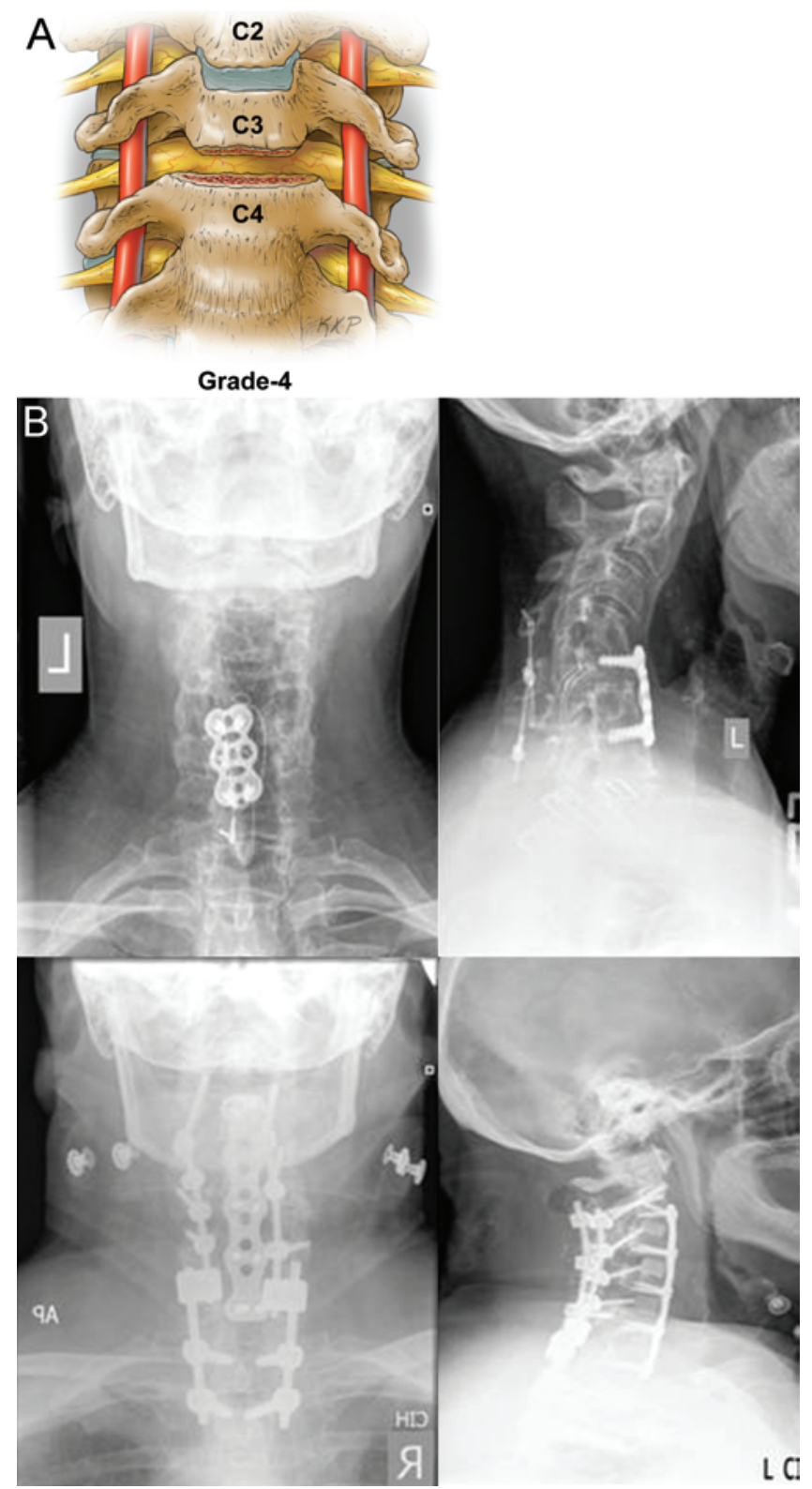

FIG. 5. A: Grade 4 osteotomy, complete uncovertebral joint resection to transverse foramen. B: Preoperative and postoperative radiographs of a patient treated with a 3-stage procedure. Stage 1 entailed posterior instrumentation removal, exploration of fusion, C3-7 laminectomy, complete facet resections from C-3 to C-5, and segmental instrumentation from C-2 to T-1. Stage 2 involved removal of anterior instrumentation, multilevel discectomy and osteotomy through the uncovertebral joints to the transverse foramen, and plating from C-3 to C-7. Stage 3 necessitated posterior rod placement, final correction, and fusion from C-2 to T-1. The classification for this case is 4PAP (with Grade 2 minor osteotomies).

the posterior elements, including the lamina, spinous process, and facets, followed by removal of the pedicles and creation of a closing wedge in the vertebral body (Fig. 7). This osteotomy is typically performed at the cervicothoracic junction (C-7 or T-1) below the entrance of the vertebral arteries into the transverse foramen at the C- 6 vertebra. Some authors favor performing this osteotomy at C-7 rather than T-1 to avoid the necessity of deep dissec- 
A

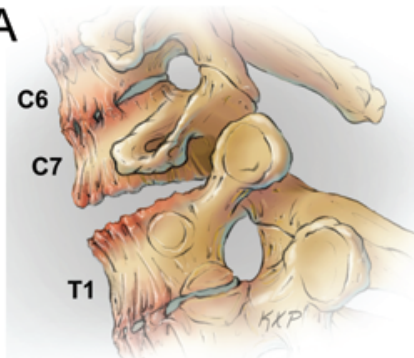

Grade-5

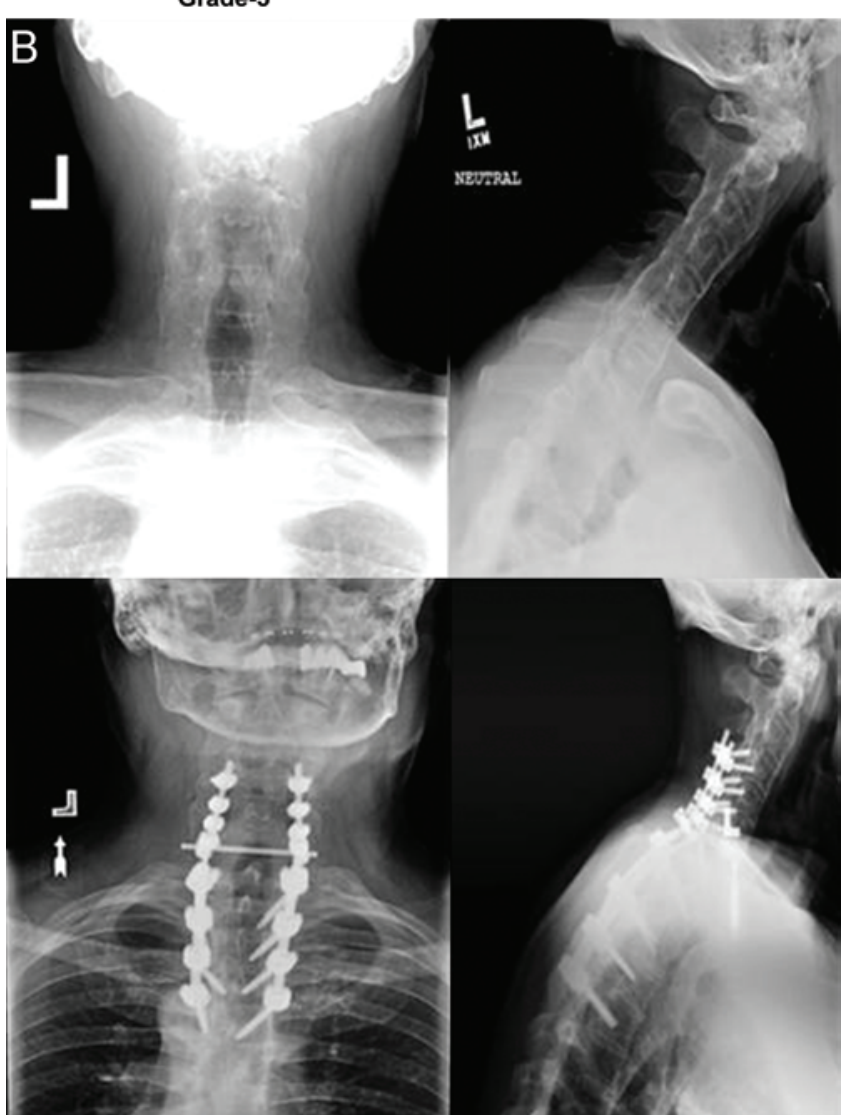

FIG. 6. A: Grade 5 osteotomy, opening wedge osteotomy. B: Preoperative and postoperative radiographs of a patient treated with posterior segmental instrumentation from C-4 to T-5, C6-T1 laminectomy, opening wedge osteotomy at C-7, rod placement, and reduction of deformity. The classification for this case is $5 \mathrm{P}$ (with no minor osteotomies).

tion for T-1 rib removal, which can be difficult. ${ }^{9}$ A closing wedge osteotomy (Grade 6) contrasts with an opening wedge osteotomy (Grade 5) in that the Grade 5 osteotomy produces an elongation of the anterior column, which has been associated with serious vascular and neurological complications, and stretching of the trachea and esophagus. ${ }^{1,16,32}$ At least in theory, the Grade 6 osteotomy may be safer than the Grade 5 osteotomy because the former does not result in stretching of the anterior structures..$^{59} \mathrm{~A}$ posterior approach (Modifier P) is used for Grade 6 osteotomies, but these may be performed in combination with an anterior release (Modifiers AP, PA, APA, or PAP).

The cervical Grade 6 osteotomy is closely analogous to the posterior decancellation osteotomy other-
A

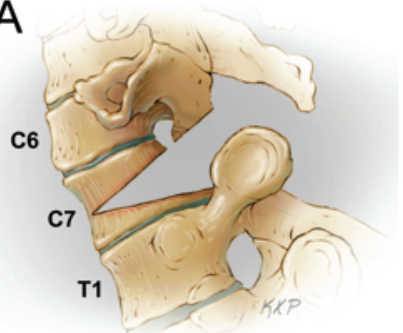

Grade-6

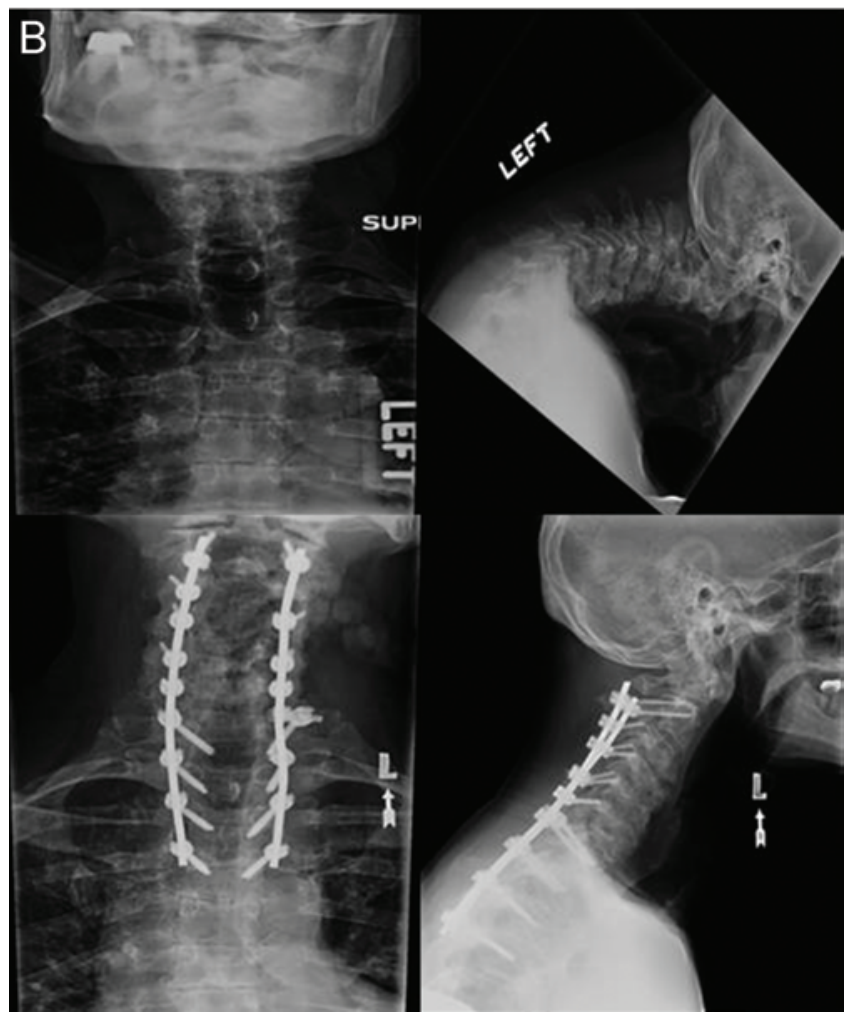

FIG. 7. A: Grade 6 osteotomy, closing wedge osteotomy. B: Preoperative and postoperative radiographs of a patient treated with posterior segmental instrumentation from C-2 to T-4, laminectomy from C-2 to T-1, pedicle subtraction osteotomy at C-7, and Smith-Petersen osteotomies at C6-7 and C7-T1. The classification for this case is 6P (with Grade 2 minor osteotomies).

wise known as the "eggshell" procedure or pedicle subtraction osteotomy, which has been applied extensively in the thoracolumbar spine for correction of deformity. $2,5,6,14,24,25,33,38,49,52,53$ Several authors have reported on their experiences with Grade 6 osteotomies for correction of cervical deformity, ${ }^{9,21,37,43,59,62}$ with the largest series to date from Deviren et al. ${ }^{9}$

\section{Grade 7: Complete Vertebral Column Resection}

A Grade 7 osteotomy includes complete resection of one or more entire vertebral bodies, including the adjacent discs, the complete uncovertebral joint, posterior lamina, and facets (Fig. 8). This osteotomy is achieved through combined approaches (Modifiers AP, PA, APA, or PAP) and typically includes placement of anterior column support that may include custom-cut fibular allograft or an expandable cage. Likely due to the complexity and risk 

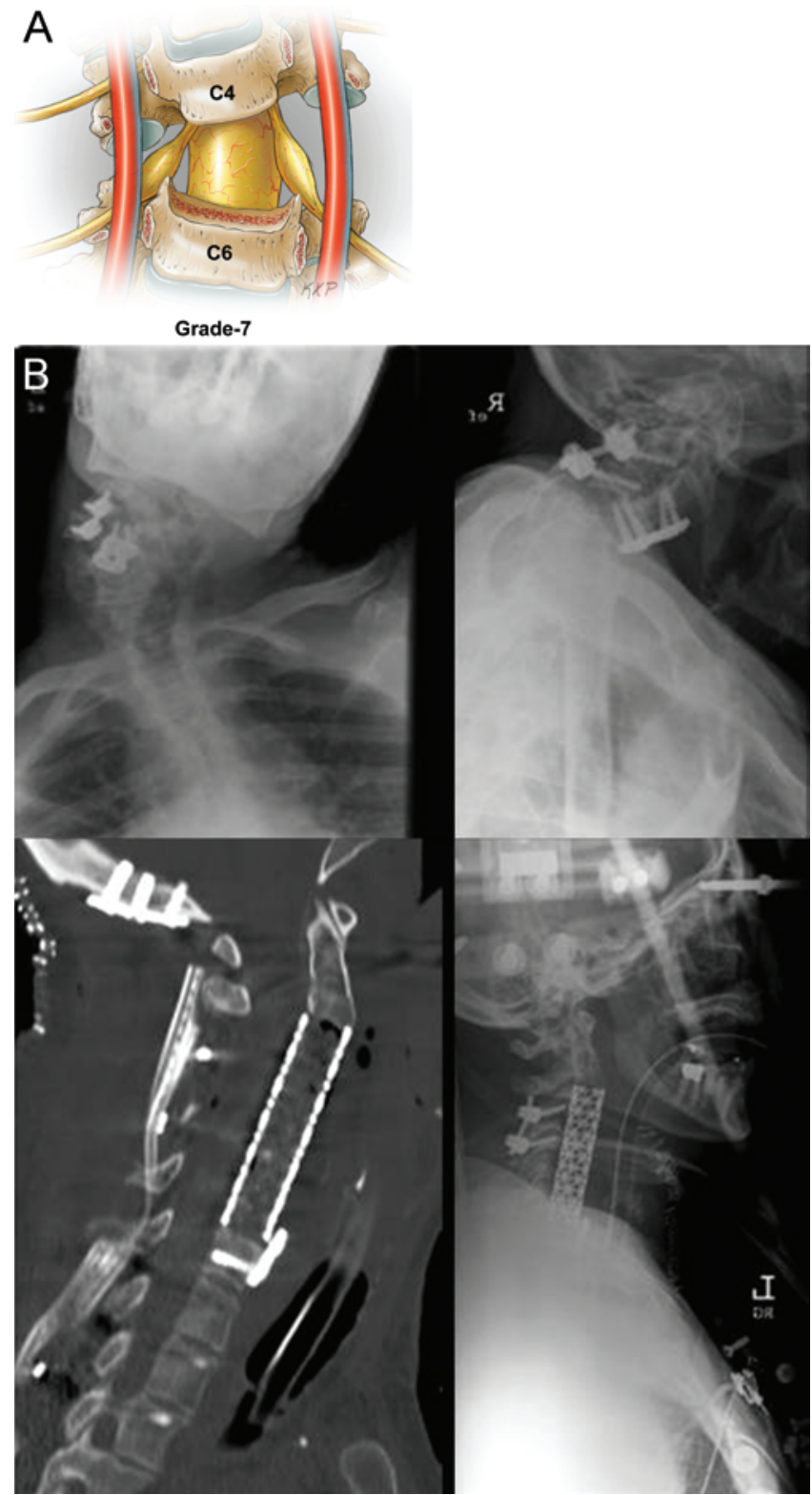

FIG. 8. A: Grade 7 osteotomy, complete vertebral column resection. B: Preoperative and postoperative radiographs of a patient treated with a 2-stage procedure. Stage 1 involved anterior removal of instrumentation, corpectomy through the uncovertebral joints to the transverse foramen bilaterally, and anterior fusion with cages placed from C-2 to C-6. Stage 2 entailed posterior removal of instrumentation, spinal fusion with instrumentation from the occiput to T-2, and posterior laminectomy and complete facet resection at C-3 to C-4. The classification for this case is 7AP (with no minor osteotomies)

of Grade 7 osteotomies, as well as the relatively limited indications, few reports of these osteotomies exist. ${ }^{10,11,15,17}$

\section{Nomenclature Reliability}

Based on the proposed nomenclature, a reliability study was performed using 25 clinical cases that were graded by 11 readers with expertise in CSD diagnosis and treatment. The readers were experienced cervical and thoracolumbar deformity surgeons and members of a large multicenter deformity study group. Cases were se- lected to be representative of all osteotomy grades. Readers were provided with pre- and postoperative cervical radiographs and portions of the operative notes and were instructed to identify the major osteotomy (the highestgrade osteotomy performed), any minor osteotomies (osteotomies of lower grades than the major osteotomy) that may have been performed, and the approach modifier for the entire case (A, P, AP, PA, APA, or PAP). The radiographic and textual descriptions provided were intended to simulate a chart review, which would expectedly include operative reports and radiographs. A minimum of 1 week following the first reading, the case order was randomized and the cases were re-sent for repeat grading. Most assessments were received back for scoring between 10-21 days after being sent to the reviewers.

A dedicated MATLAB (Mathworks) program was used to assess interrater and intrarater reliability measures based on calculations of the Fleiss kappa coefficient values. Kappa values were classified as follows: $0.00-0.20$ (slight agreement), 0.21-0.40 (fair agreement), 0.41-0.60 (moderate agreement), 0.61-0.80 (substantial agreement), and 0.81-1.00 (almost perfect agreement). ${ }^{26}$

\section{Results}

\section{Case Sample}

Twenty-five cases of CSD, with pre- and postoperative radiographic images and excerpts from the corresponding operative notes, were assembled so that the readers could assess the resection type and approach modifier. Cases were selected to include all osteotomy grades and approach modifiers, and 16 of the cases had one or more minor osteotomy performed. With regard to the major osteotomy and approach modifier, the cases were classified as follows: 4 cases were classified as Grade 1 (1 Modifier A, 2 Modifier AP, and 1 Modifier PAP); 2 cases were classified as Grade 2 (1 Modifier P and 1 Modifier PAP); 5 cases were classified as Grade 3 (1 Modifier A, 1 Modifier AP, and 3 Modifier PAP); 4 cases were classified as Grade 4 (Modifier PAP); 2 cases were classified as Grade 5 (Modifier P); 7 cases were classified as Grade 6 (4 Modifier P, 1 Modifier PA, and 2 Modifier PAP); and 1 case was classified as Grade 7 (Modifier AP).

\section{Intrarater and Interrater Reliability and Agreement}

The average intrarater reliability (Table 2) was classified as "almost perfect agreement" for the major osteotomy (0.89 (range [range 0.60-1.00]) and approach modifier (0.99 [range 0.95-1.00]); for the minor osteotomy, average intrarater reliability was classified as "moderate agreement" (0.73 [range 0.41-1.00]). The average interrater reliability (Table 3 ) for the 2 readings was the following: major osteotomy, 0.87 ("almost perfect agreement"); approach modifier, 0.99 ("almost perfect agreement"); and minor osteotomy, 0.55 ("moderate agreement"). Analysis of only major osteotomy plus approach modifier yielded a classification that was "almost perfect," with average intrarater reliability of 0.90 (range $0.63-1.00$ ) and interrater reliability of 0.88 and 0.86 for the two reviews. 
TABLE 2: Intrarater reliability for resection grade (major and minor osteotomies) and for approach modifier

\begin{tabular}{cccc}
\hline & & Intrarater Reliability & \\
\cline { 2 - 4 } Reader $\dagger$ & Major Osteotomy & Minor Osteotomy & Approach Modifier \\
\hline 1 & 0.60 & 0.41 & 1.00 \\
2 & 0.87 & 0.68 & 1.00 \\
3 & 0.96 & 0.94 & 0.95 \\
4 & 0.91 & 0.73 & 0.95 \\
5 & 0.91 & 0.81 & 1.00 \\
6 & 0.91 & 0.67 & 1.00 \\
7 & 0.82 & 0.73 & 1.00 \\
8 & 0.91 & 0.64 & 1.00 \\
9 & 0.95 & 0.55 & 0.95 \\
10 & 1.00 & 1.00 & 1.00 \\
11 & 1.00 & 0.84 & 1.00 \\
average & 0.89 & 0.73 & 0.99 \\
\hline
\end{tabular}

* Determined using the Fleiss kappa coefficient.

$\dagger$ Values are listed for each reader based on 2 readings.

\section{Discussion}

Relatively few reports detail the surgical treatment of CSD. Early reports typically included limited numbers of patients, had high complication rates, and had what were considered very high-risk procedures.,31,61 Over the last couple of decades, continued improvements in anesthesia and critical care, coupled with rapid advances in surgical techniques and spinal instrumentation, have led to expanded capabilities and renewed interests in addressing these often challenging deformities..$^{1,7-11,13-15 \text {, }}$ 17-22,36,37,39-43,45-47,53,55-60,62

Similar to the surgical treatment of thoracolumbar deformities, spinal osteotomies represent powerful techniques that enable deformity correction of the cervical spine. These osteotomies, which range from relatively limited facet joint releases to complete vertebrectomy, are complex and have evolved through generations of surgeons and reports in the literature. Previously, there has not been a comprehensive nomenclature to serve as the basis of communication among physicians and to facilitate effective clinical and radiographic assessment of patients with these deformities. In the present study, our objective was to develop a standardized nomenclature for cervical osteotomies and to demonstrate its intra- and interrater reliability among a group of experienced experts in CSD.

The proposed system is based on 7 anatomical grades of resection that represent progressively greater degrees of bony removal and potential destabilization. Since procedures for a given case may involve combinations of resection types, the highest grade of osteotomy performed is designated as the "major osteotomy," while lower grades of osteotomy are designated as "minor osteotomies." Grading of the major osteotomy had excellent intra- and interrater reliability, demonstrating that use of the proposed osteotomy classification system is consistent and reliable. Moderate reliability was shown for grading minor osteotomies based on intra- and interrater assessments. Notably, each of the 7 osteotomy grades was represented by at least one case in which it was applied as the major osteotomy, and classification of the major osteotomy had excellent reliability. This demonstrates that the defined grades are readily identifiable by the case readers. It is possible that the lesser reliability for determination of osteotomies when they were performed as minor osteotomies may relate to limitations in the operative report details provided to the reviewers.

The decision of which approach(es) (anterior and/or posterior) to use and the ordering of the approaches used to surgically address CSD can be complex and is not standardized. Therefore, as part of the proposed system, an approach modifier was included to incorporate this information. Excellent reliability was demonstrated for selection of the approach modifier, based on both intra- and interrater assessments.

TABLE 3: Interrater reliability for resection grade (major and minor osteotomies) and for approach modifier

\begin{tabular}{cccc}
\hline & & Interrater Reliability* $^{*}$ & \\
\cline { 2 - 4 } Factor† & Major Osteotomy & Minor Osteotomy & Approach Modifier \\
\hline Reading 1 & 0.89 & 0.59 & 0.97 \\
Reading 2 & 0.85 & 0.52 & 1.00 \\
average & 0.87 & 0.55 & 0.99 \\
\hline * Determined using the Fleiss kappa coefficient. & & \\
$\dagger$ Values are based on 2 readings and 11 readers. & &
\end{tabular}


Although any categorical nomenclature will have inherent limitations, the proposed approach does offer several substantial advantages over the current terminology. A graded nomenclaure of anatomical bony resection and destabilization captures variations in technique, while still allowing objective comparative analysis. The surgical approach(es) used to treat CSD are tied to the complexity of the cases and risks for complications, and the inclusion of an approach modifier allows this information to be tied to the osteotomy grade. The intent of the proposed nomenclature is to promote a more objective and consistent description of cervical osteotomies as a means of improving communication in the care of patients with CSD and in comparative studies of surgical outcomes.

\section{Conclusions}

The proposed cervical spinal osteotomy nomenclature, based on 7 resection grades and an approach modifier, provides the surgeon with a simple, standardized description of cervical osteotomies, serving as a means of improving communication and future research efforts. The reliability analysis demonstrated that this system is consistent and directly applicable. Future work will evaluate the relationship between this system and healthrelated quality of life metrics.

\section{Disclosure}

The International Spine Study Group (ISSG) is funded through research grants from DePuy Spine and individual donations.

Author contributions to the study and manuscript preparation include the following. Conception and design: Smith, Ames, Shaffrey, Deviren, Protopsaltis, Klineberg, Burton, Hart. Acquisition of data: Smith, Ames, Scheer, Lafage, Deviren, Moal, Protopsaltis, Mummaneni, Mundis, Hostin, Klineberg, Bess, Schwab. Analysis and interpretation of data: Smith, Ames, Scheer, Bess, Schwab. Drafting the article: Smith, Ames, Hart. Critically revising the article: all authors. Reviewed submitted version of manuscript: all authors. Approved the final version of the manuscript on behalf of all authors: Smith. Statistical analysis: Lafage, Moal. Study supervision: Ames.

\section{References}

1. Belanger TA, Milam RA IV, Roh JS, Bohlman HH: Cervicothoracic extension osteotomy for chin-on-chest deformity in ankylosing spondylitis. J Bone Joint Surg Am 87:1732-1738, 2005

2. Blondel B, Schwab F, Ungar B, Smith J, Bridwell K, Glassman $S$, et al: Impact of magnitude and percentage of global sagittal plane correction on health-related quality of life at 2-years follow-up. Neurosurgery 71:341-348, 2012

3. Bovill EG Jr: Osteotomy of cervical part of the spine for ankylosing spondylitis with severe deformity. Calif Med 102:142144, 1965

4. Bridwell KH: Decision making regarding Smith-Petersen vs. pedicle subtraction osteotomy vs. vertebral column resection for spinal deformity. Spine (Phila Pa 1976) 31 (19 Suppl): S171-S178, 2006

5. Bridwell KH, Lewis SJ, Lenke LG, Baldus C, Blanke K: Pedicle subtraction osteotomy for the treatment of fixed sagittal imbalance. J Bone Joint Surg Am 85-A:454-463, 2003

6. Bridwell KH, Lewis SJ, Rinella A, Lenke LG, Baldus C, Blanke $\mathrm{K}$ : Pedicle subtraction osteotomy for the treatment of fixed sagittal imbalance. Surgical technique. J Bone Joint Surg Am 86-A (Suppl 1):44-50, 2004
7. Chang KW, Cheng CW, Chen HC, Chang KI, Chen TC: Closing-opening wedge osteotomy for the treatment of sagittal imbalance. Spine (Phila Pa 1976) 33:1470-1477, 2008

8. Chavanne A, Pettigrew DB, Holtz JR, Dollin N, Kuntz C IV: Spinal cord intramedullary pressure in cervical kyphotic deformity: a cadaveric study. Spine (Phila Pa 1976) 36:16191626, 2011

9. Deviren V, Scheer JK, Ames CP: Technique of cervicothoracic junction pedicle subtraction osteotomy for cervical sagittal imbalance: report of 11 cases. Clinical article. J Neurosurg Spine 15:174-181, 2011

10. Etame AB, Than KD, Wang AC, La Marca F, Park P: Surgical management of symptomatic cervical or cervicothoracic kyphosis due to ankylosing spondylitis. Spine (Phila Pa 1976) 33:E559-E564, 2008

11. Etame AB, Wang AC, Than KD, La Marca F, Park P: Outcomes after surgery for cervical spine deformity: review of the literature. Neurosurg Focus 28(3):E14, 2010

12. Geck MJ, Macagno A, Ponte A, Shufflebarger HL: The Ponte procedure: posterior only treatment of Scheuermann's kyphosis using segmental posterior shortening and pedicle screw instrumentation. J Spinal Disord Tech 20:586-593, 2007

13. Gerling MC, Bohlman HH: Dropped head deformity due to cervical myopathy: surgical treatment outcomes and complications spanning twenty years. Spine (Phila Pa 1976) 33:E739E745, 2008

14. Gertzbein SD, Harris MB: Wedge osteotomy for the correction of post-traumatic kyphosis. A new technique and a report of three cases. Spine (Phila Pa 1976) 17:374-379, 1992

15. Han K, Lu C, Li J, Xiong GZ, Wang B, Lv GH, et al: Surgical treatment of cervical kyphosis. Eur Spine J 20:523-536, 2011

16. Herbert JJ: Vertebral osteotomy for kyphosis, especially in Marie-Strumpell arthritis; a report on fifty cases. J Bone Joint Surg Am 41-A:291-302, 1959

17. Hoh DJ, Khoueir P, Wang MY: Management of cervical deformity in ankylosing spondylitis. Neurosurg Focus 24(1):E9, 2008

18. Iwasaki M, Yamamoto T, Miyauchi A, Amano K, Yonenobu $\mathrm{K}$ : Cervical kyphosis: predictive factors for progression of kyphosis and myelopathy. Spine (Phila Pa 1976) 27:1419-1425, 2002

19. Kanter AS, Wang MY, Mummaneni PV: A treatment algorithm for the management of cervical spine fractures and deformity in patients with ankylosing spondylitis. Neurosurg Focus 24(1):E11, 2008

20. Kawahara N, Tomita K, Baba H, Kobayashi T, Fujita T, Murakami $\mathrm{H}$ : Closing-opening wedge osteotomy to correct angular kyphotic deformity by a single posterior approach. Spine (Phila Pa 1976) 26:391-402, 2001

21. Kim KT, Lee SH, Son ES, Kwack YH, Chun YS, Lee JH: Surgical treatment of "chin-on-pubis" deformity in a patient with ankylosing spondylitis: a case report of consecutive cervical, thoracic, and lumbar corrective osteotomies. Spine (Phila Pa 1976) 37:E1017-E1021, 2012

22. Kuntz C IV, Levin LS, Ondra SL, Shaffrey CI, Morgan CJ: Neutral upright sagittal spinal alignment from the occiput to the pelvis in asymptomatic adults: a review and resynthesis of the literature. J Neurosurg Spine 6:104-112, 2007

23. Labelle H, Mac-Thiong JM, Roussouly P: Spino-pelvic sagittal balance of spondylolisthesis: a review and classification. Eur Spine J 20 (Suppl 5):641-646, 2011

24. Lafage V, Schwab F, Vira S, Hart R, Burton D, Smith JS, et al: Does vertebral level of pedicle subtraction osteotomy correlate with degree of spinopelvic parameter correction? Clinical article. J Neurosurg Spine 14:184-191, 2011

25. Lafage V, Smith JS, Bess S, Schwab FJ, Ames CP, Klineberg E, et al: Sagittal spino-pelvic alignment failures following three column thoracic osteotomy for adult spinal deformity. Eur Spine J 21:698-704, 2012 
26. Landis JR, Koch GG: The measurement of observer agreement for categorical data. Biometrics 33:159-174, 1977

27. Law WA: Osteotomy of the spine. Clin Orthop Relat Res 66: 70-76, 1969

28. Lenke LG, Betz RR, Haher TR, Lapp MA, Merola AA, Harms J, et al: Multisurgeon assessment of surgical decisionmaking in adolescent idiopathic scoliosis: curve classification, operative approach, and fusion levels. Spine (Phila Pa 1976) 26:2347-2353, 2001

29. Lenke LG, Betz RR, Harms J, Bridwell KH, Clements DH, Lowe TG, et al: Adolescent idiopathic scoliosis: a new classification to determine extent of spinal arthrodesis. J Bone Joint Surg Am 83-A:1169-1181, 2001

30. Lu DC, Chou D: Flatback syndrome. Neurosurg Clin N Am 18:289-294, 2007

31. Mason C, Cozen L, Adelstein L: Surgical correction of flexion deformity of the cervical spine. Calif Med 79:244-246, 1953

32. McMaster MJ: Osteotomy of the cervical spine in ankylosing spondylitis. J Bone Joint Surg Br 79:197-203, 1997

33. McMaster MJ: A technique for lumbar spinal osteotomy in ankylosing spondylitis. J Bone Joint Surg Br 67:204-210, 1985

34. Mehdian S, Arun R: A safe controlled instrumented reduction technique for cervical osteotomy in ankylosing spondylitis. Spine (Phila Pa 1976) 36:715-720, 2011

35. Mehdian SM, Freeman BJ, Licina P: Cervical osteotomy for ankylosing spondylitis: an innovative variation on an existing technique. Eur Spine J 8:505-509, 1999

36. Moore RE, Dormans JP, Drummond DS, Shore EM, Kaplan FS, Auerbach JD: Chin-on-chest deformity in patients with fibrodysplasia ossificans progressiva. A case series. J Bone Joint Surg Am 91:1497-1502, 2009

37. Mummaneni PV, Dhall SS, Rodts GE, Haid RW: Circumferential fusion for cervical kyphotic deformity. Clinical article. J Neurosurg Spine 9:515-521, 2008

38. Murrey DB, Brigham CD, Kiebzak GM, Finger F, Chewning SJ: Transpedicular decompression and pedicle subtraction osteotomy (eggshell procedure): a retrospective review of 59 patients. Spine (Phila Pa 1976) 27:2338-2345, 2002

39. Nottmeier EW, Deen HG, Patel N, Birch B: Cervical kyphotic deformity correction using 360-degree reconstruction. J Spinal Disord Tech 22:385-391, 2009

40. O'Shaughnessy BA, Liu JC, Hsieh PC, Koski TR, Ganju A, Ondra SL: Surgical treatment of fixed cervical kyphosis with myelopathy. Spine (Phila Pa 1976) 33:771-778, 2008

41. Petheram TG, Hourigan PG, Emran IM, Weatherley CR: Dropped head syndrome: a case series and literature review. Spine (Phila Pa 1976) 33:47-51, 2008

42. Poulter GT, Garton HJ, Blakemore LC, Hensinger RN, Graziano GP, Farley FA: Mortality and morbidity associated with correction of severe cervical hyperextension. Spine (Phila Pa 1976) 34:378-383, 2009

43. Samudrala S, Vaynman S, Thiayananthan T, Ghostine S, Bergey DL, Anand N, et al: Cervicothoracic junction kyphosis: surgical reconstruction with pedicle subtraction osteotomy and Smith-Petersen osteotomy. Clinical article. J Neurosurg Spine 13:695-706, 2010

44. Sansur CA, Fu KM, Oskouian RJ Jr, Jagannathan J, Kuntz C IV, Shaffrey CI: Surgical management of global sagittal deformity in ankylosing spondylitis. Neurosurg Focus 24(1):E8, 2008

45. Scheer JK, Tang JA, Buckley JM, Deviren V, Pekmezci M, McClellan RT, et al: Biomechanical analysis of osteotomy type and rod diameter for treatment of cervicothoracic kyphosis. Spine (Phila Pa 1976) 36:E519-E523, 2011

46. Scheer JK, Tang JA, Deviren V, Acosta F, Buckley JM, Pekmezci M, et al: Biomechanical analysis of cervicothoracic junction osteotomy in cadaveric model of ankylosing spondylitis: effect of rod material and diameter. Laboratory investigation. J Neurosurg Spine 14:330-335, 2011
47. Scheer JK, Tang JA, Smith JS, Acosta FL, Protopsaltis TS, Blondel B, et al: Cervical spine alignment, sagittal deformity, and clinical implications. A review. J Neurosurg Spine [epub ahead of print June 14, 2013. DOI: 10.3171/2013.4. SPINE12838]

48. Schwab F, Ungar B, Blondel B, Buchowski J, Coe J, Deinlein D, et al: Scoliosis Research Society-Schwab adult spinal deformity classification: a validation study. Spine (Phila Pa 1976) $37: 1077-1082,2012$

49. Schwab FJ, Patel A, Shaffrey CI, Smith JS, Farcy JP, BoachieAdjei O, et al: Sagittal realignment failures following pedicle subtraction osteotomy surgery: are we doing enough? Clinical article. J Neurosurg Spine 16:539-546, 2012

50. Simmons EH: Kyphotic deformity of the spine in ankylosing spondylitis. Clin Orthop Relat Res (128):65-77, 1977

51. Simmons EH: The surgical correction of flexion deformity of the cervical spine in ankylosing spondylitis. Clin Orthop Relat Res 86:132-143, 1972

52. Smith JS, Shaffrey CI, Ames CP, Demakakos J, Fu KM, Keshavarzi S, et al: Assessment of symptomatic rod fracture after posterior instrumented fusion for adult spinal deformity. Neurosurgery 71:862-867, 2012

53. Smith JS, Shaffrey CI, Lafage V, Blondel B, Schwab F, Hostin R, et al: Spontaneous improvement of cervical alignment after correction of global sagittal balance following pedicle subtraction osteotomy. Clinical article. J Neurosurg Spine 17:300-307, 2012

54. Smith-Petersen MN, Larson CB, Aufranc OE: Osteotomy of the spine for correction of flexion deformity in rheumatoid arthritis. Clin Orthop Relat Res 66:6-9, 1969

55. Steinmetz MP, Stewart TJ, Kager CD, Benzel EC, Vaccaro AR: Cervical deformity correction. Neurosurgery 60 (1 Supp1 1): S90-S97, 2007

56. Stewart TJ, Steinmetz MP, Benzel EC: Techniques for the ventral correction of postsurgical cervical kyphotic deformity. Neurosurgery 56 (1 Suppl):191-195, 2005

57. Suk KS, Kim KT, Lee SH, Kim JM: Significance of chin-brow vertical angle in correction of kyphotic deformity of ankylosing spondylitis patients. Spine (Phila Pa 1976) 28:20012005, 2003

58. Tang JA, Scheer JK, Smith JS, Deviren V, Bess S, Hart RA, et al: The impact of standing regional cervical sagittal alignment on outcomes in posterior cervical fusion surgery. Neurosurgery 71:662-669, 2012

59. Tokala DP, Lam KS, Freeman BJ, Webb JK: C7 decancellisation closing wedge osteotomy for the correction of fixed cervico-thoracic kyphosis. Eur Spine J 16:1471-1478, 2007

60. Uchida K, Nakajima H, Sato R, Yayama T, Mwaka ES, Kobayashi S, et al: Cervical spondylotic myelopathy associated with kyphosis or sagittal sigmoid alignment: outcome after anterior or posterior decompression. Clinical article. J Neurosurg Spine 11:521-528, 2009

61. Urist MR: Osteotomy of the cervical spine; report of a case of ankylosing rheumatoid spondylitis. J Bone Joint Surg Am 40-A:833-843, 1958

62. Wollowick AL, Kelly MP, Riew KD: Pedicle subtraction osteotomy in the cervical spine. Spine (Phila Pa 1976) 37:E342E348, 2012

Manuscript submitted November 21, 2012.

Accepted May 21, 2013.

Please include this information when citing this paper: published online July 5, 2013; DOI: 10.3171/2013.5.SPINE121067.

Address correspondence to: Justin S. Smith, M.D., Ph.D., Department of Neurosurgery, University of Virginia Health Sciences Center, PO Box 800212, Charlottesville, VA 22908. email: jss7f@ virginia.edu. 